\title{
The need for simplified design guides of in filled RC frames with confined openings
}

\begin{abstract}
Infilled RC frames, mostly with opening, have been widely used construction type that is not listed in most building codes as seismic-force-resisting systems. Ignoring the existence of infill wall in RC frame design, however, may result in unfavorable mode of failure. Therefore, simplified design guide is necessary to encourage structural engineers to include the contribution of infill wall to the lateral stiffness and capacity of the RC frame.
\end{abstract}

Keywords: modeling techniques, infilled frame, design guide, confined opening
Volume 3 Issue 5 - 2017

\author{
Made Sukrawa \\ Civil Engineering Department, Udayana University, Indonesia
}

Correspondence: Made Sukrawa, Civil Engineering Department, Udayana University, Badung, Bali, Indonesia, Email msukrawa@yahoo.com

Received: May 24, 2017 | Published: November 14, 2017

\section{Mini review}

Intra Infilled reinforced concrete (RC) frame (IF) is one of the most common types of structures used in low and medium rise building, especially in the area where affordable materials and labor are available, including in the area with high seismicity. Opening on the wall is part of the architectural design to house windows and doors of various sizes and location within the wall. Though opening may reduce the lateral strength and stiffness of the corresponding solid infilled frame (Solid-IF), it cannot be overlooked in the design as the composite action between the RC frame and infill wall may negatively affect the behavior of IF like in the case of soft storey, short column mechanism, and brittle failure of the frame. Nonetheless, considering the complex, non-linear behavior of IF structures, a simpler and practical design guides is required to encourage structural engineers to include the contribution of infill walls in their analysis and designs, and therefore, more accurate behavior and failure mechanism of the structure is possible.

Research on IF with wall opening (IFO) has been repeatedly reported in the form of experimental testing and analytical modeling. They all agreed that despite the opening, the lateral strength and stiffness of IFO is still greater than that of the corresponding bare frame (BF) acting alone. Moreover, if reinforcement in the form of lintel or tie-columns were present around the wall opening, the ductility of IFO was greatly enhanced by the confinement provided by the tiecolumns. This important phenomenon was observed from test results reported by Sigmund \& Penava. ${ }^{1}$ The perception of brittle failure mechanism of IFO can now be redefined through the introduction of confinement around the opening as in the case of confined masonry.

Earlier studies on IFO did not include confinement on the wall opening, although many design guidelines recommend their usage for larger opening size. Kakaletsis \& Karayannis, ${ }^{2}$ tested 8 simple, $1 / 3$ scale IFOs of varying opening type and location to be compared to Solid-IF and BF, using normal strength concrete of $28.5 \mathrm{MPa}$ and masonry of 3.1 MPa. It was shown that, compare to the OF, the IFOs have greater initial lateral stiffness (1.57-2.14) with lateral resistance of 1.25-1.64. They introduced serviceability limit state at a drift between $0.27 \%$ and $0.39 \%$. The drift at which lateral resistance is reduced to $85 \%$ of the peak resistance ranged from $1.87 \%$ to $3.48 \%$. Stavridis. ${ }^{3}$ reported quasistatic and dynamic tests on IF and IFOs together with finite element (FE) models using combination of smeared and discrete crack approaches. The materials strength and length scale were different for each specimen. He observed that the corner of window opening was the weakest point of the infill walls where crack initiated at lower load level. Figure 1 shows comparison of failure mechanism from test and FEA results of the 2/3-scaled specimen of IFO at a drift value of $1 \%$ together with the corresponding load-drift curve. He pointed out that between the drift range of 0.5 and $1 \%$ the IFO exhibited complex behavior that cannot be fully captured even by the detailed finite element models. Never the less, he point out that there was no significant load drop in the post peak behavior of shaketable specimen until a lateral drift close to $1 \%$. Beyond this point the specimen collapsed due to shear failure of column and detachment of triangular piece of infill wall around the window. Scaling effect was also an important finding that the result from small scaled specimen should be interpreted with caution (Figure 1).

The effect of confinement around the opening of infill wall was investigated by Sigmund \& Penava. ${ }^{1}$ by testing 10 frames of $1: 2.5$ scale, 4 IFOs with lintel only on top of the opening (group I: 1/I-4/I), 4 IFOs with lintels on top and tie-columns on both sides of the opening extended from the tie beam to the top frame (group II: 1/ II-4/II). The other two was BF and Solid-IF (group III: 1/III and 2/ III) used for comparison. Using characteristic compressive strength of $45 \mathrm{MPa}$ for the frame concrete and $30 \mathrm{MPa}$ for the tie columns concrete to confine masonry wall of $2.7 \mathrm{MPa}$, it was revealed that the lateral stiffness and capacity of IFOs was not much different to that of the Solid-IF and the addition of tie-columns around the opening did not change the overall stiffness and capacity of the framedwall specimen. However, confinement provided by the tie-columns affected the failure mechanism of the IFO, increased the ductility, and equalized the behavior of the infill. They also observed a range of drift ratios and lateral loads associated with the wall damage level of insignificant, moderate, heavy, and collapse. At drift ratio of $0.1 \%$ the damage level is insignificant for all groups, and at drift of $1 \%$ the walls were collapse for group II and III. The wall with window opening in group I were collapse at drift greater than $1 \%$ while the wall with door opening collapse at drift of less than $1 \%$. These results proofed that the addition of tie-columns equalized the behavior of the infill wall. Heavy damage for the wall in group II was observed at drift between $0.36 \%$ and $0.57 \%$. The numbers can be regarded as serviceability limit state for IFO with confined opening, compared to $0.27 \%$ and $0.39 \%$ value for IFO without confinement. 

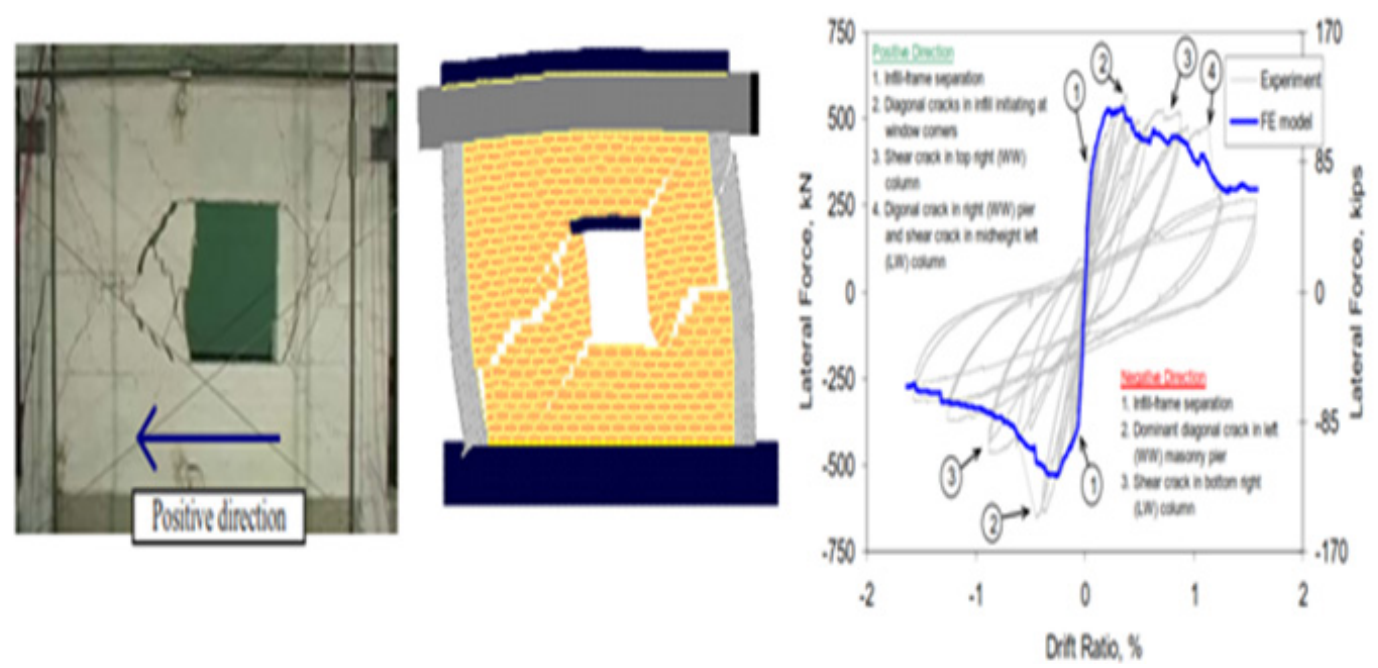

Figure I Failure mechanism and load-drift curve of IFO from test and FE model results (cracks at corner of opening).

Using test results from, ${ }^{1}$ Asteris et al. ${ }^{4}$ proposed a coefficient to reduce the width of strut of solid infill recommended in FEMA 306. The coefficient approached zero for opening ratio of $50 \%$ or greater. Based on test results of IFOs of group I, Sigmund and Penava. 5 proposed a design methodology for IFO using equivalent diagonal strut method by introducing a correction factor to reduce the width of strut for solid IF. The factor however, is dependant of selected damage state which is not easy to calculate. Stavridis, ${ }^{3}$ noted that though the opening size is influential at the initial loading stages, there was no distinct trend between the opening size and the peak strength and failure mechanism. Opening location is more important than the opening size. All of the above mentioned test results support this statement. Construction of tie-columns for opening area of $1.5 \mathrm{~m}^{2}$ or greater are recommended in the design guidelines of many building codes including Eurocode. ${ }^{6}$ FEMA 273 implicitly suggest the use of tie-column by specifying $40 \%$ maximum length of openings of the overall wall length to be considered to act compositely. The need for tie-columns around the wall opening can be shown in a simple FE models by Sukrawa. ${ }^{6}$ The significant improvement of the behavior of masonry with confinement can be seen in confined masonry construction. The extended tie-column around the opening are effective in improving stability and integrity of masonry walls for in-plane and out-of-plane earthquake effects. ${ }^{7}$

Up to now, FEMA 306 provide formula to calculate diagonal strut width only for Solid-IF, none for infilled-panel with opening. In FEMA P-750 / 2009 new structural systems are added to the table of design coefficient and factors for seismic-force-resisting systems, including AAC shear wall. However, IF is not yet on the list. More data on actual performance of IFO under seismic load is required in addition to test results, preferably on bigger scale specimens, for the development of response modification coefficient (R) and deflection amplification factor (Cd). The $\mathrm{R}$ and $\mathrm{Cd}$ value can be used to convert results from linear elastic analysis to include the inelastic effect. The design guidelines may include the use of tie-columns and anchorage of masonry wall into the frame. In the construction of low rise building of IF system, the extra cost of tie-columns around the opening can be balanced by easier installation of door or window frames made of wood or aluminum, in addition to the higher ductility of the structures. The absence of these $\mathrm{R}, \mathrm{Cd}$, and design guidelines is a challenge for future research.

\section{Funding}

None.

\section{Acknowledgments}

None.

\section{Conflicts of interest}

None.

\section{References}

1. V Sigmund, D Penava. Experimental study of masonry infilled R/C frames with openings, 15 WCEE, Lisboa, Croatia. 2012.

2. DJ Kakaletsis, CG Karayannis. Experimental investigation of infilled Reinforced Concrete frames with openings. ACI Struc J. 2009;106(2):132141.

3. A Stavridis. Analytical and experimental study of seismic performance of reinforced concrete frames infilled with masonry walls. UC San Diego. 2009.

4. PG Asteris, IP Giannopoulos, CZ Chrysostomou. Modeling of infilled frames with openings. The Open Construction and Building Technology Journal. 2012;6(1-6):81-91.

5. V Sigmund, D Penava. Assesment of masonry infilled RC frames with openings. Tehnicki vjesnik. 2013;20(3):459-466.

6. M Sukrawa. Earthquake response of RC infilled frame with wall openings in low-rise hotel buildings. Procedia Engineering. 2015;125:933-939. 